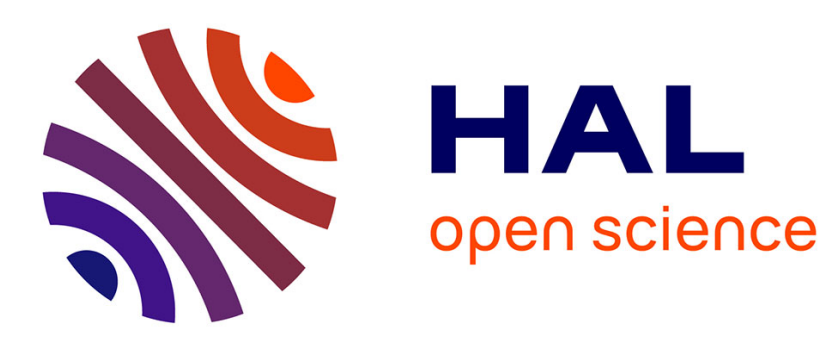

\title{
NARROW-BAND ULTRA-LOW CURRENT MEASUREMENTS WITH A RF SQUID
}

F. Bordoni, P. Carelli, I. Modena, G. Romani

\section{To cite this version:}

F. Bordoni, P. Carelli, I. Modena, G. Romani. NARROW-BAND ULTRA-LOW CURRENT MEASUREMENTS WITH A RF SQUID. Journal de Physique Colloques, 1978, 39 (C6), pp.C6-1213-C61214. 10.1051/jphyscol:19786536 . jpa-00218023

\section{HAL Id: jpa-00218023 https://hal.science/jpa-00218023}

Submitted on 1 Jan 1978

HAL is a multi-disciplinary open access archive for the deposit and dissemination of scientific research documents, whether they are published or not. The documents may come from teaching and research institutions in France or abroad, or from public or private research centers.
L'archive ouverte pluridisciplinaire HAL, est destinée au dépôt et à la diffusion de documents scientifiques de niveau recherche, publiés ou non, émanant des établissements d'enseignement et de recherche français ou étrangers, des laboratoires publics ou privés. 


\title{
NARROW-BAND ULTRA-LOW CURRENT MEASUREMENTS WITH A RF SQUID
}

\author{
F. Bordoni, P. Carel1i ${ }^{+}$, I. Modena ${ }^{+}$and G.L. Romani ${ }^{+}$
}

Laboratomio Plasma Spazio - C.N.R. - C.P. 27-Frascati . Italy
+Laboratomo Elettronica Stato Solido - C.N.R. Via Cineto Romano 42 - Rome - Italy

\begin{abstract}
Résumé.- L'utilisation d'un transformateur à noyau ferromagnétique couplé à un SQUID permet de mesurer de très faibles courants, comme nous 1 'avons précédemment montré. L'utilisation d'un noyau céramique à faible pertes pour le transformateur a permis d'augmenter ultérieurement la sensibilité de presque deux ordres de grandeur dans une bande étroite autour d'une fréquence donnée. Actuellement on obtient une sensibilité de presque $8 \times 10^{-4}$ pA dans une largeur de bande de 1 Hz à $150 \mathrm{~Hz}$.
\end{abstract}

Abstract.- The use of a ferromagnetic transformer coupled to a SQUID, as previously described, permits to measure very low currents. A low loss ceramic core for the transformer has yielded to further increase in the sensitivity of about two orders of magnitude in a narrow-band around a fixed frequency. At present the achieved sensitivity of about $8 \times 10^{-4} \mathrm{pA}$ in $1 \mathrm{~Hz}$ bandwidth at $150 \mathrm{~Hz}$.

The use of a superconducting magnetometer as a high sensitivity current detector has been proposed by some authors a few years ago /1,2,3/. More recently, by coupling a transformer with a ferromagnetic core to a rf SQUID /4/, we have enhanced the overall current sensitivity up to very interesting figures /5/. Due to the particular ferromagnetic material employed $/ 6 /$ the useful bandwidth of the device was constrained between dc and a corner frequency dictated by the strong frequency dependence of the relative permeability of the used core. In order to enhance the current sensitivity at a fixed frequency we inserted a tuning capacitor in the input circuit. However, due to the high value of the electrical conductivity of the core a large amount of eddy-current losses was present, limiting the $Q$ of the urned circuit to not interesting values. This drawback has been overcome by means of a suitable choice of a ceramic core for. the transformer. We have tested a few commercially available ferrites in order to select those which preserve an acceptable value of the relative permeability at $1 i-$ quid helium temperature. The chosen material has been used to make up a superconducting transformer coupled to the SUID as shown in figure 1. The current I $(v)$ is supplied by a current generator I to the input circuit which consists of a capacitance $C$ paralleled to the primary $\mathrm{L}_{\mathrm{T}}\left(\mathrm{N}_{\mathrm{T}}\right.$ turns) of the transformer. The secondary winding $L_{P}$ ( $N_{P}$ turns) is connected with the inductance $\mathrm{L}_{S}$ to obtain as usual a flux transformer. Al1 windings are made of superconducting wire. $\mathrm{M}_{\mathrm{TP}}=\mathrm{K}_{\mathrm{TP}} \sqrt{\mathrm{L}_{\mathrm{T}} \mathrm{L}_{\mathrm{P}}}$ is the mutual inductance between $\mathrm{L}_{T}$ and $\mathrm{L}_{\mathrm{P}}$, while $\mathrm{M}=\mathrm{K} \sqrt{\mathrm{L}_{\mathrm{S}} \mathrm{L}}$ is the mutual inductance between $\mathrm{L}_{S}$ and the inductance of the SQUID, L.

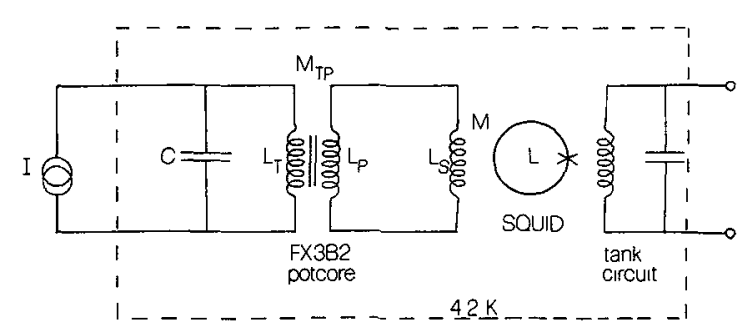

Fig. 1 : Schematic of the experimental arrangement used for narrow-band ultra-low current measurements. The room temperature current generator I feeds the "tuned" input circuit $\mathrm{C}, \mathrm{L}_{\mathrm{T}}: \mathrm{L}_{\mathrm{T}}$ and $\mathrm{L}_{\mathrm{P}}$ are wound over the ferromagnetic core. All inductances $L_{T} \cdot I_{P}$ and $L_{S}$ are made up with superconducting wire. For other symbols meaning see text.

A straightforward analysis /5/ of the circuit of figure 1 shows that, once the matching condition for the flux transformer is satisfied, i.e. $I_{P} \approx L_{S}$ "in situ", the current sensitivity of the device is enhanced by a factor $\approx \frac{N_{T} K_{T P}}{2 N_{T}}$ below the resonance frequency. At resonance a further gain is obtained, given by the factor of merit $Q$ of the input circuit.

A typical experimental result obtained with this technique is shown in figure 2, where the input current $i^{\circ}(\nu)$, which causes the SQUID to slip one flux quantum, is reported versus frequency. Data are taken with the following set of experimental parameters : $\mathrm{C}: 0.312 \mathrm{HF}, \mathrm{N}_{\mathrm{T}}=8360, \mathrm{~N}_{\mathrm{P}}=6$, $\mathrm{K}_{\mathrm{TP}}=0.95, \mathrm{~L}_{\mathrm{S}}=10.5 \mu \mathrm{H}$.

A11 superconducting coils have been wound using a $50 \mu \mathrm{m}$ formwar insulated $\mathrm{Nb}$ wire. One 
One Phillips "potcore" Ferroxcube 3B2 grade has been used for the transformer : geometrical dimensions of the core obviously constrained the maximum number of turns for the primary winding $\mathrm{L}_{\mathrm{T}}$.

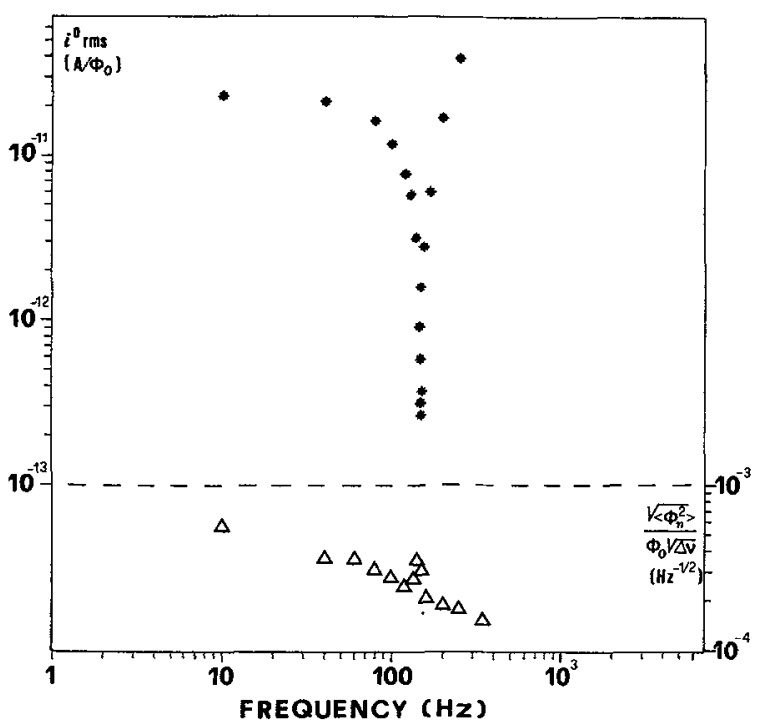

Fig. 2 : ( $\left(\right.$ ) : experimental behavior $i^{\circ}$ rms versus frequency ; $i^{\circ}$ is the current which, flowing in the input "tuned" circuit causes the SQUID to slip one flux quantum. Experimental values of the relevant parameters are: $\mathrm{N}_{\mathrm{T}}=8360, \mathrm{~N}_{\mathrm{P}}=6, \mathrm{~L}_{\mathrm{S}}=10.5 \mu \mathrm{H}$, $\mathrm{L}=4.2 \times 10^{-10} \mathrm{H}, \mathrm{K}_{\mathrm{TP}}=0.95, \mathrm{M}=5.95 \times 10^{-8} \mathrm{H}$ and $\mathrm{C}=0.312 \mu \mathrm{F}$.

$(\triangle)$ : measured root-mean square flux noise values in units of $\phi_{0}$ per $H z^{3 / 2}$ versus frequency.

A two-hole symetric SQUID ( $\mathrm{L}=4.2 \times 10^{-10} \mathrm{H}$ ) has been used to obtain a value for $M$ as large as possible. With the value of the inductance $\mathrm{L}_{S}$ mentioned above we achieved experimental value for the mutual inductance $\mathrm{M}=5.75 \times 10^{-8} \mathrm{H}$. The measured value of $i^{\circ} \approx 22 \mathrm{pA} / \phi_{0}$ at frequencies below resonance we11 agrees with the calculated value $i_{c}^{\circ} \approx$ $\frac{\phi_{0}}{\mathrm{M}} \frac{2 \mathrm{~N}_{\mathrm{P}}}{\mathrm{K}_{\mathrm{TP}} \mathrm{N}_{\mathrm{T}}} \approx 20 \mathrm{pA} / \phi_{\mathrm{O}}$. It is evident from data figure 2 that an improvement in current sensitivity of about two orders of magnitude at a fixed frequency is obtained by means of resonance.

As the ultimate performances of the system are determined by the signal to noise ratio, it is important to know the ouput noise spectrum. In figure 2 we also report the measured output noise expressed in flux quantum units per $\sqrt{\mathrm{Hz}}$ versus frequency. Noise measurements haze been performed sending the "linearized" SQUID output to a lock-in used as a narrow-band amplifier, the output of which is suc- cessively squared and integrated. Data show that the output noise is moderately dependent on the frequency : its value, at resonance, is only about one order of magnitude larger than the value obtainable with the SQUID not coupled to a transformer. This means that, at the resonance frequency, the minimum detectable current, in $1 \mathrm{~Hz}$ bandwidth, is $i_{\min } \approx 0.8 \times 10^{-15} \mathrm{~A}$.

The sensitivity of the device is limited by the relatively low value of the factor of merit of the input circuit $(Q \approx 85)$. This drawback doesn't seem due to losses in the ferrite core. The properties of the ceramic core as given by factory's specifications should yield to a $Q$ several order of magnitude larger than the measured one. Moreover the sma11 Q-value cannot be due to losses in the capacitance, because of the above mentioned behavior of the noise versus frequency. We believe that the limitations to the resonant gain in the input circuit may be justified as due to an input dissipative term of the SQUID, which should be reported into the input circuit, increased by a factor $\approx \mathrm{N}^{2}$. The authors are indebted to Prof. R.P. Giffard for useful discussions.

\section{References}

/1/ Clarke, J., Tennant, W.E. and Woody, D. : J. Appl. Phys. 42 (1971) 3859.

/2/ Davidson, A., Newsbower, R.S. and Beasley, M.R. Rev. Sci. Instrum. 45 (1974) 838.

13/ Claassen, J.H., J. App1. Phys. 46 (1975) 2268

14/ Care11i, P., Modena, I. and Romani, G.L., Advance in Cryogenics Engineering 23 (1978) 512.

/5/ Barbanera, S., Carel1i, P., Modena, I. and Romani, G.L., J. Appl. Phys. (1978) in press.

/6/ Cryoperm 10 supplied by Vacuumschmeltz G.M.B.H. Hanau, W. Germany. 